\title{
Patterns of pleural pressure amplitude and respiratory rate changes during therapeutic thoracentesis
}

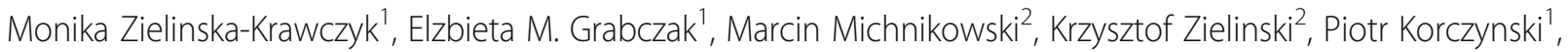
Anna Stecka ${ }^{2}$, Tomasz Golczewski ${ }^{2}$ and Rafal Krenke ${ }^{1 *}$

\begin{abstract}
Background: Although the impact of therapeutic thoracentesis on lung function and blood gases has been evaluated in several studies, some physiological aspects of pleural fluid withdrawal remain unknown. The aim of the study was to assess the changes in pleural pressure amplitude ( $\mathrm{Ppl}_{\mathrm{ampl}}$ ) during the respiratory cycle and respiratory rate (RR) in patients undergoing pleural fluid withdrawal.
\end{abstract}

Methods: The study included 23 patients with symptomatic pleural effusion. Baseline pleural pressure curves were registered with a digital electronic manometer. Then, the registrations were repeated after the withdrawal of consecutive portions of pleural fluid $(200 \mathrm{ml}$ up to $1000 \mathrm{ml}$ and $100 \mathrm{ml}$ above $1000 \mathrm{ml}$ ). In all patients the pleural pressure curves were analyzed in five points, at 0,25\%,50\%,75\% and $100 \%$ of the relative volume of pleural effusion withdrawn in particular patients.

Results: There were 11 and 12 patients with right sided and left sided pleural effusion, respectively $(14 \mathrm{M}, 9 \mathrm{~F}$, median age 68, range 46-85 years). The most common cause of pleural effusion were malignancies (20 pts., $87 \%$ ). The median total volume of withdrawn pleural fluid was 1800 (IQR 1500-2400) ml. After termination of pleural fluid withdrawal Pplampl increased in 22/23 patients compared to baseline. The median Pplampl increased from 3.4 (2.4-5. 9) $\mathrm{CmH}_{2} \mathrm{O}$ to $10.7(8.1-15.6) \mathrm{cmH}_{2} \mathrm{O}(p<0.0001)$. Three patterns of $\mathrm{Ppl}_{\text {ampl }}$ changes were identified. Although the patterns of RR changes were more diversified, a significant increase between RR at baseline and the last measurement point was found ( $p=0.0097$ ).

Conclusions: In conclusion, therapeutic thoracentesis is associated with significant changes in Pplampl during the respiratory cycle. In the vast majority of patients Pplampl increased steadily during pleural fluid withdrawal. There was also an increase in RR. The significance of these changes should be elucidated in further studies.

Trial registration: ClinicalTrial.gov, registration number: NCT02192138, registration date: July 1st, 2014.

Keywords: Pleural effusion, Pleural fluid, Pleural pressure, Thoracentesis, Pleural manometry, Pleural pathophysiology

\footnotetext{
* Correspondence: rkrenke@wum.edu.pl

${ }^{1}$ Department of Internal Medicine, Pulmonary Diseases \& Allergy, Medical

University of Warsaw, Banacha 1a, 02-097 Warsaw, Poland

Full list of author information is available at the end of the article
} 


\section{Background}

Large volume pleural effusion leads to an increase in pleural pressure, negatively affects lung volumes and induces clinical symptoms (e.g. dyspnea and cough) [1-3]. Conversely, therapeutic thoracentesis usually results in a decrease in pleural pressure and has beneficial effects on pulmonary function [2, 4, 5]. Although the number of thoracenteses performed in the USA is reported between 127,000 and 173,000 procedures per year [6, 7], some physiological aspects of pleural fluid removal have not been adequately studied. This is partly because there is no universal and commonly accepted animal model for studying pleural pathophysiology. The relationship between pleural fluid volume and pulmonary function has been evaluated in several human studies. These studies showed that the increase in forced expiratory volume at first second $\left(\mathrm{FEV}_{1}\right)$ and forced vital capacity $(\mathrm{FVC})$ after therapeutic thoracentesis approximates $20-30 \%$ of the withdrawn pleural fluid volume [4, 8-10]. Changes in spirometric parameters in patients undergoing therapeutic thoracentesis were related to pleural pressure (Ppl). In a study by Light et al. [4], higher postthoracentesis Ppl and smaller Ppl decrease after pleural fluid removal were associated with a more significant improvement in FVC.

Some other studies focused on the effect of therapeutic thoracentesis on blood gases. A study by Brandstetter and Cohen [11] showed that $\mathrm{PaO}_{2}$ decreases significantly early after therapeutic thoracentesis and returns to pre-thoracentesis value after $24 \mathrm{~h}$. Different results were reported in later studies. Perpina et al. found a significant increase in $\mathrm{PaO}_{2}$ after pleural fluid removal reaching a maximum at $24 \mathrm{~h}$, while Agusti et al. reported no significant effect of therapeutic thoracentesis on blood gases $[12,13]$. Changes in blood gases after therapeutic thoracentesis were also studied in relation to pleural pressure and pleural elastance $[14,15]$. Chen et al. reported a significantly larger increase in $\mathrm{PaO}_{2}$ and $\mathrm{PaO}_{2} / \mathrm{FiO}_{2}$ ratio in patients with normal pleural elastance $\left(\mathrm{PE}<14 \mathrm{cmH}_{2} \mathrm{O} / \mathrm{L}\right)$ compared to patients with high $\left(>14 \mathrm{cmH}_{2} \mathrm{O} / \mathrm{L}\right)$ pleural elastance.

The use of digital pleural manometers not only allows to precisely assess pleural elastance during pleural fluid removal but also enables monitoring $\mathrm{Ppl}$ changes in different phases of the respiratory cycle. In our previous studies we observed some changes in Ppl curve characteristics during pleural fluid withdrawal $[16,17]$. These included an increase in $\mathrm{Ppl}$ amplitude during the respiratory cycle and changes in respiratory rate. To our knowledge, this effect has not been evaluated and described in details so far. Therefore, we undertook a study aimed at the evaluation of changes in the respiratory pattern and pleural pressure amplitude associated with therapeutic thoracentesis.

\section{Methods}

\section{Study design}

This prospective, study was performed between January 2016 and August 2016. Consecutive patients with large volume pleural effusion referred to our department to perform therapeutic thoracentesis were enrolled. The study protocol was approved by the Institutional Review Board (KB 105/2012) and registered at ClinicalTrial.gov (NCT02192138). As the study was a part of larger project, the patients signed an informed consent for pleural pressure monitoring during and after therapeutic thoracentesis, as well as for all additional monitoring procedures (e.g. lung function) included in the study protocol.

\section{Patients}

The specific inclusion criteria were as follows: (1) age between 18 and 85 years, (2) pleural effusion occupying at least one third of the ipsilateral hemithorax in posteroanterior chest radiograph (CXR), (3) no contraindications for therapeutic thoracentesis, (4) general health condition allowing prolonged procedure of therapeutic thoracentesis.

\section{Methods}

Therapeutic thoracentesis was performed in sitting position. Small bore pleural catheter (outer diameter $8 \mathrm{Ch}$, i.e. $2.67 \mathrm{~mm}$, length $12.5 \mathrm{~cm}$; Turkel ${ }^{\mathrm{Tm}}$ Safety System, Covidien, Whiteley Fareham, UK) was inserted to the pleural cavity in the dependent region under real-time ultrasound guidance. Pressure transducer and electronic manometer were connected to the pleural catheter via 3-way stopcock and carefully purged of air with sterile saline as described elsewhere [16]. The vertical reference point for a pressure of zero was defined at the level of catheter insertion into the chest. Then, the 3-way stopcock was connected to the pleural catheter and baseline pleural pressure curve was registered before beginning of pleural fluid withdrawal. Pleural fluid was aspirated with a $60 \mathrm{ml}$ syringe. Pleural pressure curve was subsequently registered after withdrawal of each $200 \mathrm{ml}$ of pleural fluid up to a total volume of $1000 \mathrm{ml}$. The duration of pleural pressure registration in each volume point was $60 \mathrm{~s}$. When the volume of the removed fluid exceeded $1000 \mathrm{ml}$, registrations were performed after removal of each $100 \mathrm{ml}$. Vital signs and symptoms were registered together with pleural pressure changes. The pleural fluid withdrawal was terminated when one of the following occurred: (1) there was no more fluid in the pleural cavity, (2) poor procedure tolerance, i.e. onset or worsening of symptoms (e.g. severe dyspnea, chest pain, tachycardia, hemodynamic instability) with or without significant drop in Ppl $\left(<-20 \mathrm{cmH}_{2} 0\right)$. The pleural catheter was fixed to the chest wall, purged with sterile 
saline and left in place for subsequent measurements not reported in this article.

Pleural pressure curves were recorded during quiet tidal breathing. A special software was developed to perform a reliable analysis after the completion of pleural fluid withdrawal. In all patients the pleural pressure curves were analyzed in five points that reflected the relative volume of withdrawn pleural effusion, i.e. \% of the total volume of pleural fluid removed in a particular patient (Fig. 1a). First, baseline data were assessed and then the calculations were repeated after 25\%, 50\%, 75\% and $100 \%$ of total fluid volume withdrawn in a particular patient. In each measurement point at least five consecutive and comparable cycles of pleural pressure changes were selected for analysis (Fig. 1b). The following parameters were calculated: respiratory rate, mean and median pleural pressure (mean $\mathrm{Ppl}$, median $\mathrm{Ppl}$ ), end-expiratory pleural pressure (end-exp $\mathrm{Ppl}$ ), endinspiratory pleural pressure (end-insp $\mathrm{Ppl}$ ), pleural pressure amplitude during a respiratory cycle $\left(\mathrm{Ppl}_{\mathrm{ampl}}=\right.$ endexp $\mathrm{Ppl}$ - end-insp Ppl), total time of respiratory cycle (Fig. 1c). Also, pleural elastance was calculated as the change in pleural pressure (the difference between the baseline and closing pressure) divided by the volume of withdrawn pleural effusion $[2,3,15]$.

\section{Statistical analysis}

Data are presented as medians and interquartile ranges (IQRs, 25th to 75th percentiles). Statistical analysis was performed using Statistica 12.0 (StatSoft Inc., Tulsa, USA) and MedCalc Statistical Software version 13.2.2
(MedCalc Software bvba, Ostend, Belgium). Quantitative data distribution was assessed using the Shapiro-Wilk test. Analysis of variance of $\mathrm{Ppl}_{\mathrm{ampl}}$ and RR in predefined points reflecting the relative volume of withdrawn pleural fluid was performed using Friedman's test. The Wilcoxon test was used to compare the differences between parameters in two different points of assessment. The differences between continuous variables in two independent groups were tested using the non-parametric Mann-Whitney U-test. The strength and direction of the linear relationship between two variables was measured with Spearman's rank correlation coefficient. All $P$ values were 2 -tailed and $P<0.05$ was considered statistically significant.

\section{Results}

Twenty-six patients were initially enrolled. However, three patients had to be excluded from final analysis due to low quality of measurements, i.e. high variability of pleural pressure curve that did not allow reliable calculation of $\mathrm{Ppl}$ and $\mathrm{Ppl}_{\mathrm{ampl}}$. Thus, the investigated group included 23 patients (14 M, 9F, median age 68, range 4685 ). There were 11 patients with right- and 12 patients with left-sided pleural fluid. Malignant, parapneumonic and rheumatoid pleural effusion was diagnosed in 20, 2 and 1 patient, respectively.

The volume of pleural fluid removed in different points of assessment and pleural elastance

The data on the volume of pleural fluid removed in five different points of assessment are presented in Table 1 .

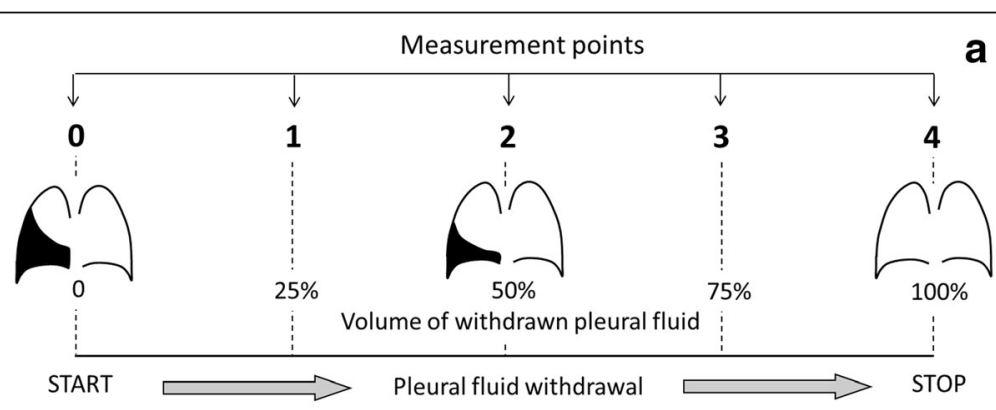

b

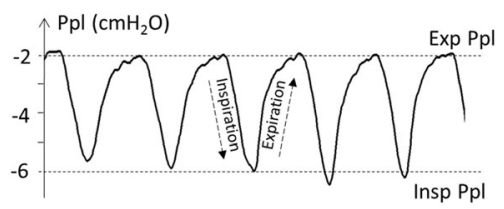

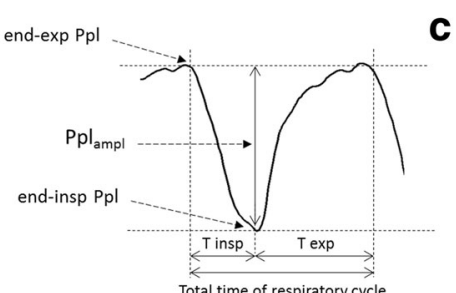

Fig. 1 Methods of pleural pressure measurement and analysis. a Five points selected for analysis and their relation to the relative volume of removed pleural fluid $(0,25 \%, 50 \%, 75 \%$ and $100 \%$ of total removed volume). b An example of pleural pressure curve reflecting five respiratory cycles that was selected for analysis in each point. c Enlarged pleural pressure curve registered during one respiratory cycle and parameters that were measured: end-exp Ppl - end-expiratory pleural pressure, end-insp Ppl - end-inspiratory pleural pressure, T insp - inspiratory time, T exp. - expiratory time, Pplampl - pleural pressure amplitude during a respiratory cycle 
Table 1 The volume of removed pleural fluid in different points of assessment

\begin{tabular}{llllll}
\hline Volume of removed PF & \multicolumn{4}{l}{ Point of assessment } & \\
\cline { 2 - 5 } & 0 & $1(25 \%)$ & $2(50 \%)$ & $3(75 \%)$ & 1350 \\
\hline median $(\mathrm{ml})$ & 0 & 450 & 900 & $1100 \%)$ \\
IQR (25-75 percentile) $(\mathrm{ml})$ & 0 & $375-600$ & $750-1200$ & 1800 \\
\hline
\end{tabular}

The median of total volume of pleural fluid withdrawn in 23 patients was $1800(1500-2400) \mathrm{ml}$.

The median elastance in the whole group was 8.56 (3.72-11.77) $\mathrm{cmH}_{2} \mathrm{O} / \mathrm{L}$. In 18 patients the elastance was lower than $14.5 \mathrm{cmH}_{2} \mathrm{O} / \mathrm{L}$, in 3 it was slightly elevated $\left(15.8,16.9\right.$ and $17.8 \mathrm{cmH}_{2} \mathrm{O} / \mathrm{L}$ ), while in 2 other it was very high (76.51 and $104.9 \mathrm{cmH}_{2} \mathrm{O}$ ). In these 2 last patients trapped lung was diagnosed. In 2 other patients small asymptomatic pneumothoraces were found in chest radiographs performed after the completion of the procedure. Hence, in these patients pleural elastance was low, pneumothorax ex vacuo was rather unlikely.

\section{Changes in pleural pressure amplitude ( $\left.\mathrm{Ppl}_{\mathrm{ampl}}\right)$ during pleural fluid withdrawal}

Significant unidirectional changes in $\mathrm{Ppl}_{\mathrm{ampl}}$ were found during pleural fluid withdrawal (Friedman test, $p<$ 0.0001) (Fig. 2). The median $\mathrm{Ppl}_{\mathrm{ampl}}$ increased from 3.4 (2.4-5.9) $\mathrm{cmH}_{2} \mathrm{O}$ at baseline (point 0), to 10.7 (8.1-15.6) $\mathrm{cmH}_{2} \mathrm{O}$ after termination of thoracentesis (point 4).

A highly significant increase in $\mathrm{Ppl}_{\mathrm{ampl}}$ was demonstrated between all pairs of measurements, except those between point 2 and 3 as well as 3 and 4 (Table 2). Even though the differences between $\mathrm{Ppl}_{\mathrm{ampl}}$ in points 2 vs 3 and 3 vs 4 were not statistically significant, there was a

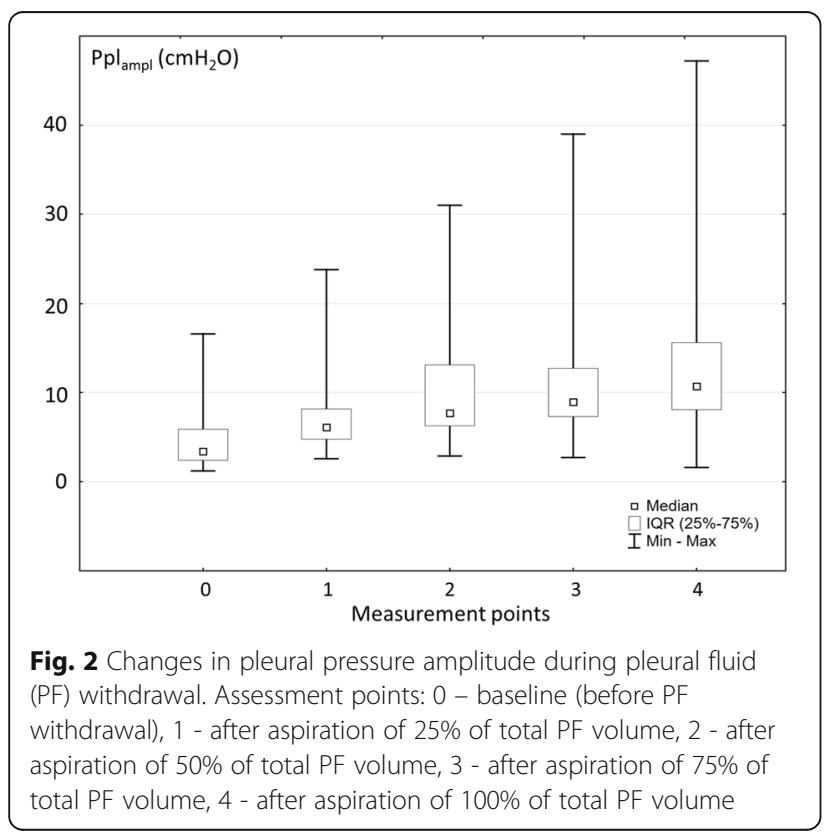

numerical increase in $\mathrm{Ppl}_{\mathrm{ampl}}$ between those points: 7.7 (6.3-13.1) vs $8.9(7.3-12.7) \mathrm{cmH}_{2} \mathrm{O}$ and 8.9 (7.3-12.7) vs $10.7(8.1-15.6) \mathrm{cmH}_{2} \mathrm{O}$, respectively.

Curves representing changes in $\mathrm{Ppl}_{\mathrm{ampl}}$ during therapeutic thoracentesis in individual patients are shown in Fig. 3a. Three slightly different patterns of $\mathrm{Ppl}_{\mathrm{ampl}}$ changes were found. In $2 / 3$ of patients $(15 / 23)$, a systematic increase in all consecutive points of measurement was noted (Fig. 3b). In 5 patients there was an increase in $\mathrm{Ppl}_{\mathrm{ampl}}$ between 0 and 2 nd point or 0 and 3rd point with decrease in the last phase of the procedure (Fig. 3c). In 3 patients $\mathrm{Ppl}_{\mathrm{ampl}}$ increased during the procedure with transitional drop between point 2 and 3 (Fig. 3d).

\section{Changes in RR during pleural fluid withdrawal}

Significant changes in RR were found during pleural fluid withdrawal (Friedman's test, $p<0.0001$ ) (Fig. 4). The median RR increased from 24.9 (20.7-28.0) per minute at baseline to 28.7 (23.7-33.7) per minute after termination of thoracentesis (point 4).

A significant increase between RR measured in points $0,1,2,3$ and that found in point 4 was demonstrated (Table 3). The transitional decrease in RR between points 0 and 1 (seen in Fig. 4) 24.9 (20.7-28.0) vs 21.8 (19.1-26.3) was statistically insignificant (Table 3, Wilcoxon test, $p=0.1070)$. There was a systematic and significant increase between RR measured in point 1 and all consecutive points.

Figure 5 shows curves representing changes in RR during therapeutic thoracentesis in individual patients. In Fig. 5a all curves are presented, while Fig. 5b-d show curves with relatively similar characteristics.

There were no statistically significant correlations between $\mathrm{Ppl}_{\mathrm{ampl}}$ and $\mathrm{RR}$ in any of the measurement points. However, highly significant correlations between pleural $\mathrm{Ppl}_{\mathrm{ampl}}$ and pleural elastance were demonstrated with $\mathrm{r}$ and $\mathrm{P}$ reaching 0.67 and 0.0006 , respectively, in the last point of assessment (point 4). Also, significant negative correlations between $\mathrm{Ppl}_{\mathrm{ampl}}$ and mean $\mathrm{Ppl}$ in points 3 and 4 were found $(r=-0.596, P=0.0034$ and $r=-$ $0.633, P=0.0016$; respectively). We did not find any significant and reliable differences between clinical parameters in patients with different patterns of $\mathrm{Ppl}_{\mathrm{ampl}}$ changes. In particular, there was no difference between the pleural elastance $(p=0.3342)$, systolic and diastolic blood pressure, and respiratory rate. 
Table 2 Differences between Pplampl in particular points of measurements

\begin{tabular}{|c|c|c|c|c|c|}
\hline Assessment point & 0 & 1 & 2 & 3 & 4 \\
\hline 0 & $x$ & $p<0.0001$ & $p<0.0001$ & $p<0.0001$ & $\mathrm{p}<0.0001$ \\
\hline 1 & $\mathrm{p}<0.0001$ & $x$ & $p<0.0001$ & $p=0.0002$ & $p=0.0001$ \\
\hline 2 & $p<0.0001$ & $p<0.0001$ & $x$ & $p=0.0945$ & $p=0.0047$ \\
\hline 3 & $\mathrm{p}<0.0001$ & $p=0.0002$ & $p=0.0945$ & $x$ & $p=0.0573$ \\
\hline 4 & $\mathrm{p}<0.0001$ & $p=0.0001$ & $p=0.0047$ & $p=0.0573$ & $x$ \\
\hline
\end{tabular}

Each point of assessment (rows) was compared with all next points of assessment (columns). $P$ for all pairs (Wilcoxon test) are presented with $P$ values $<0.05$ shown in bold

\section{Discussion}

Our study showed different patterns of $\mathrm{Ppl}_{\mathrm{ampl}}$ and $\mathrm{RR}$ changes during pleural fluid withdrawal. Despite an extensive search of the literature, we could not find any earlier publications reporting the above aspects of therapeutic thoracentesis. The only study that reported $\mathrm{Ppl}_{\text {ampl }}$ measurements (described as pleural pressure swings) was that of Boshuizen et al. However, the authors presented only the difference between $\mathrm{Ppl}_{\mathrm{ampl}}$ after removal of $200 \mathrm{ml}$ of pleural fluid in terms of expandable vs unexpandable lung [18]. Hence, we believe, our paper may be the first report on $\mathrm{Ppl}_{\mathrm{ampl}}$ during therapeutic thoracentesis.

The principle finding of the study is a relatively consequent increase in $\mathrm{Ppl}_{\mathrm{ampl}}$ that follows pleural fluid withdrawal. The $\mathrm{Ppl}_{\mathrm{ampl}}$ at the end of thoracentesis was higher in all but one patient (95.6\%) compared to $\mathrm{Ppl}_{\mathrm{ampl}}$ measured directly after pleural catheter insertion. In $65 \%$ of patients the $\mathrm{Ppl}_{\mathrm{ampl}}$ increased steadily during the procedure. In $13 \%$, there was a transient decrease in the third phase (between points 2 and 3 ) of the procedure with further significant increase in the fourth phase (between points 3 and 4), while in the remaining 22\% patients steady increase in $\mathrm{Ppl}_{\text {ampl }}$ was noted in the first two or three phases with a decrease in the last phase of the procedure. Thus, we believe, three different patterns of $\mathrm{Ppl}_{\mathrm{ampl}}$ changes during pleural fluid withdrawal can be distinguished. When patients with pattern 1 (steady increase) were compared to patients with pattern 3 (initial increase followed by a decrease) in terms of withdrawn pleural fluid volume, pleural pressure changes during the procedure and other parameters, no differences between

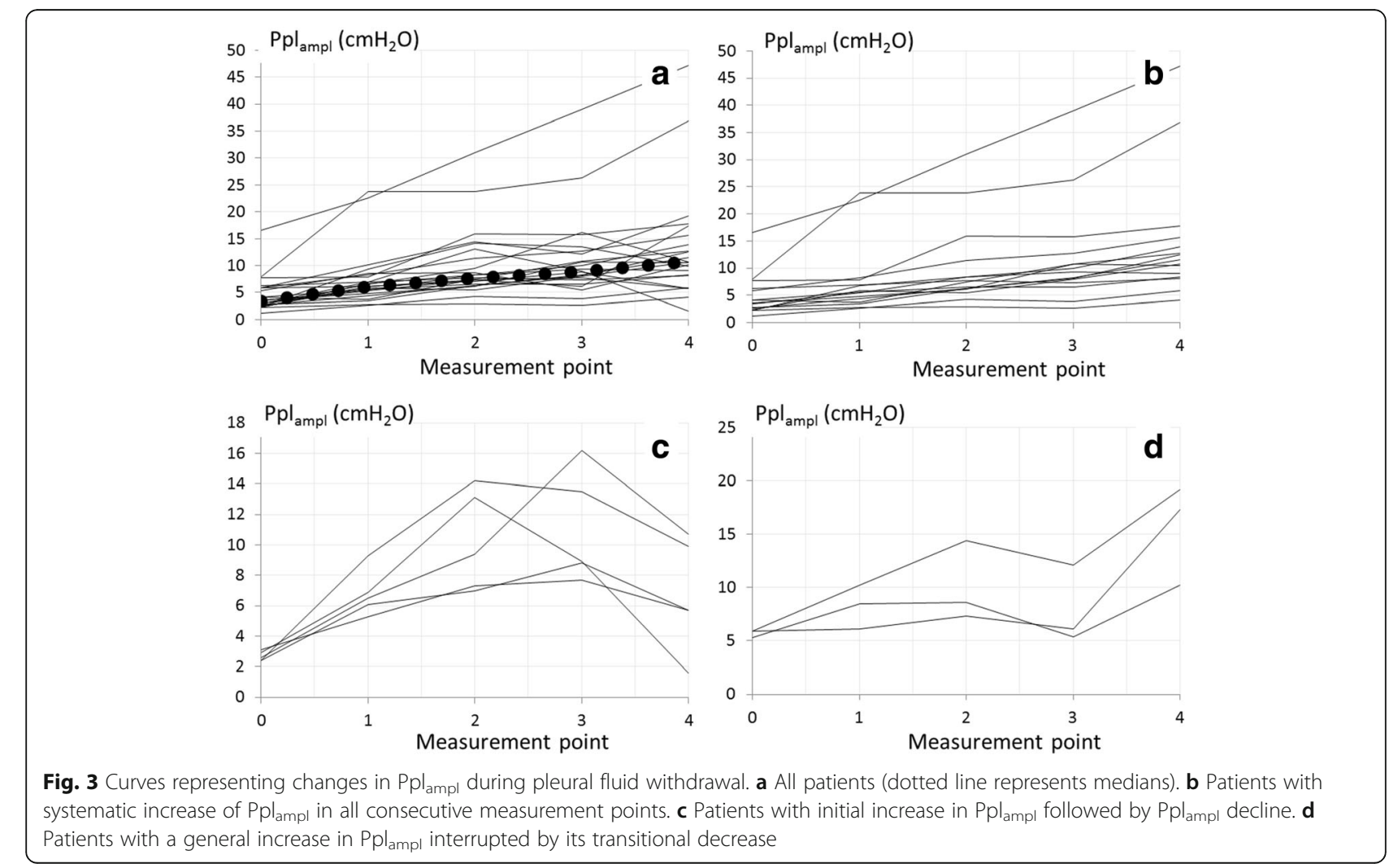




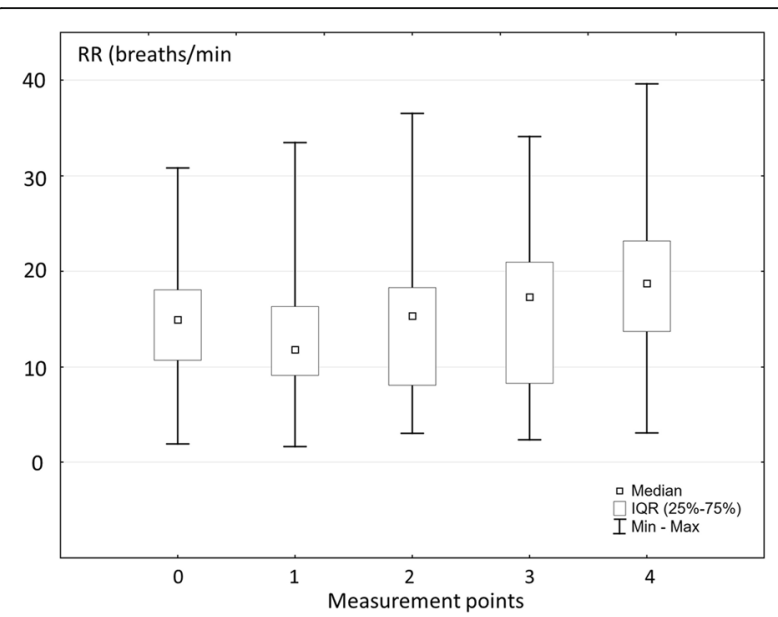

Fig. 4 Changes in respiratory rate (RR) during pleural fluid (PF) withdrawal. PF - pleural fluid; assessment points: 0 - baseline (before PF withdrawal), 1 - after aspiration of $25 \%$ of total PF volume, 2 - after aspiration of $50 \%$ of total PF volume, 3 - after aspiration of $75 \%$ of total PF volume, 4 - after aspiration of $100 \%$ of total PF volume

these two groups were noted, except median $\mathrm{Ppl}_{\mathrm{ampl}}$ at the completion of pleural fluid withdrawal (11.5 IQR 8.3-15.6 vs 5.7 IQR 5.7-9.9, respectively; $p=0.04$ ). When patients were divided into two groups based on median baseline $\mathrm{Ppl}_{\mathrm{ampl}}$ (below 3.4 and above $3.4 \mathrm{~cm} \mathrm{H}_{2} \mathrm{O}$ ) we found that the volume of withdrawn pleural fluid and pleural elastance were lower in low median baseline $\mathrm{Ppl}_{\mathrm{ampl}}$ group (1760 vs $2150 \mathrm{ml}$ and 8.05 vs $12.68 \mathrm{cmH}_{2} \mathrm{O} / \mathrm{L}$, respectively). Hence, we may speculate about the potential relationship between these parameters and the difference between $\mathrm{Ppl}_{\mathrm{ampl}}$ at the end of pleural fluid withdrawal.

The variability in $R R$ changes during the procedure was noticeably higher than that found for $\mathrm{Ppl}_{\mathrm{ampl}}$. In general, an increase in RR was found between the first (baseline) and the last measurement point $(p=0.0097)$. This was the case in $20 / 23(87 \%)$ patients. The most common pattern of RR changes during pleural fluid withdrawal was its initial decrease followed by a steady increase. Nonetheless, this pattern was demonstrated in only approximately $1 / 3$ of patients. The other characteristics of RR changes found in $17 \%$ and $22 \%$ of patients were steady and slow increase from point 0 to point 1 and initial increase with decrease in the last point (or two last points) of measurements, respectively. In the remaining $26 \%$ of patients different, difficult to categorize RR changes were observed.

As there were no earlier studies on $\mathrm{Ppl}_{\mathrm{ampl}}$ changes during therapeutic thoracentesis, we could not compare our results with other reports. The data on RR changes are also scarce with one study showing a decrease in RR from $19.4 \pm 6.5$ to $15.5 \pm 6.3$ after drainage of significant pleural effusion [19]. It should be emphasized, however, that the above study was performed in critically ill surgical patients who were on volume-regulated mechanical ventilation.

The paucity of data, together with the initial character of our report and relatively small study group, makes the explanation of our findings challenging. It could have been hypothesized that the overall increase in the respiratory system compliance associated with pleural fluid removal would result in decreased pleural pressure amplitude rather than in its increase. With higher respiratory system compliance, lower transpulmonary pressure should be sufficient to maintain or even increase tidal volume and minute ventilation. On the other hand, it could have been argued that the changes in $\mathrm{Ppl}_{\mathrm{ampl}}$ would supposedly be mainly associated with the elastic properties of the lung and visceral pleura. If so, the expansion of lung elastic elements associated with increasing lung volume due to decreasing $\mathrm{Ppl}$ that follows pleural fluid withdrawal would result in higher transpulmonary pressure required to maintain tidal volume and minute ventilation. The decline in lung compliance resulting from stretching of its elastic elements associated with lung re-expansion may be particularly significant in the atelectatic lung characterized by relative surfactant deficiency or dysfunction. We believe, the above reasoning is fully consistent with our findings of increasing $\mathrm{Ppl}_{\mathrm{ampl}}$ and RR during therapeutic thoracentesis. Significant negative correlation between $\mathrm{Ppl}_{\mathrm{ampl}}$ and $\mathrm{Ppl}$ and positive correlation between $\mathrm{Ppl}_{\mathrm{ampl}}$ and pleural elastance may further support the correctness of our interpretations.

We think that even if the differences in $R R$ were relatively small and their clinical relevance might be questioned, our findings may raise new questions on dyspnea perception, changes in voluntary ventilation and work of breathing after therapeutic thoracentesis.

Table 3 Differences between respiratory rate (RR) in particular points of measurements

\begin{tabular}{|c|c|c|c|c|c|}
\hline Assessment point & 0 & 1 & 2 & 3 & 4 \\
\hline 0 & $x$ & $p=0.1070$ & $p=0.3458$ & $p=0.1485$ & $p=0.0097$ \\
\hline 1 & $p=0.1070$ & $x$ & $p=0.0284$ & $p=0.0039$ & $p=0.0001$ \\
\hline 2 & $p=0.3458$ & $p=0.0284$ & $x$ & $p=0.3019$ & $p=0.0024$ \\
\hline 3 & $p=0.1485$ & $p=0.0039$ & $p=0.3019$ & $x$ & $p=0.0192$ \\
\hline 4 & $p=0.0097$ & $p=0.0001$ & $p=0.0024$ & $p=0.0192$ & $x$ \\
\hline
\end{tabular}

Each point (column 1) was compared with all the next points of assessment. $P$ for all pairs (Wilcoxon test) are presented with $P$ values $<0.05$ shown in bold 

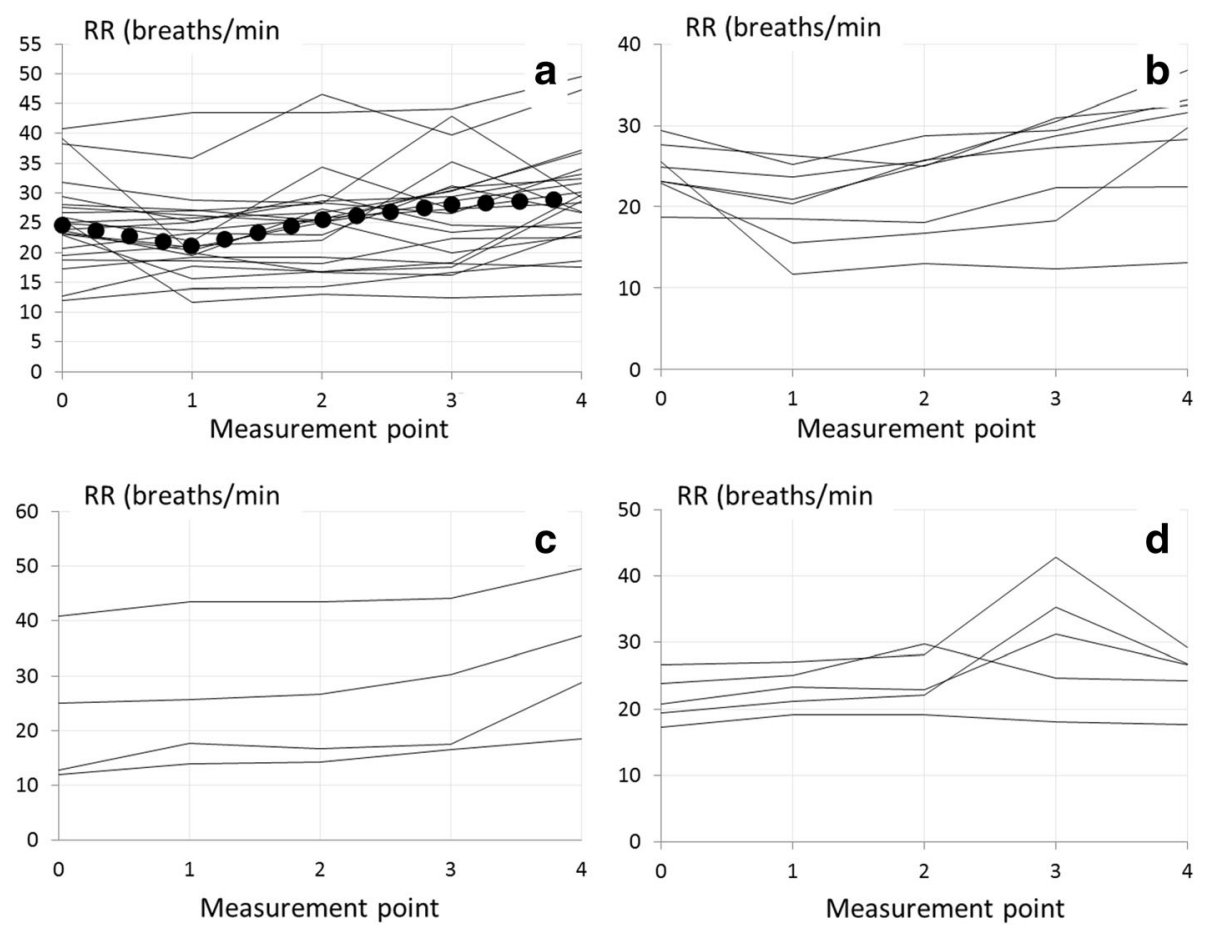

Fig. 5 Curves representing changes in respiratory rate (RR) during pleural fluid withdrawal. a All patients (dotted line represents medians). b Patients with initial decline followed by increase of RR in the next measurement points. c Patients with small, but steady increase in RR. $\mathbf{d}$ Patients with stable RR followed by its increase in 2nd or 3rd point and decrease at the termination of the procedure

Although pleural fluid withdrawal reduces dyspnea in nearly all patients, the mechanism of this phenomenon is unclear. As improvement in lung function parameters is relatively small and data on blood gases are equivocal, it has been postulated that this is mainly related to the reduced pressure on the diaphragm and subsequent restoration of its normal shape which enables inspiratory muscles to work on a more advantageous position [20, $21]$. One study showed that during pleural fluid drainage, the neural impulses from mechanoreceptors located in muscles, chest wall and lung parenchyma significantly contributed to the perception of breathlessness and indirectly influenced the respiratory rate [22]. Paradoxically, the increasing $\mathrm{Ppl}_{\mathrm{ampl}}$ during therapeutic thoracentesis found in our study may suggest an increased work of breathing rather than its reduction. It is not known whether the increased $\mathrm{Ppl}_{\mathrm{ampl}}$ is associated with increased tidal volume and minute ventilation. These, and other questions should be answered in further studies which would involve continued measurement of air flow through the airways enabling estimation of tidal volume and the minute ventilation.

A prerequisite for our study on the physiological effects of pleural fluid and therapeutic thoracentesis is pleural manometry. Although pleural pressure measurement was commonly applied to create and maintain artificial pneumothorax used to treat tuberculosis a century ago, its modern use in studying pleural pathophysiology began in early 1980 s and was associated with impressive results presented by Light and colleagues [23]. The authors demonstrated three different patterns of pleural elastance which were further confirmed in other studies [24-26]. However, water manometers or modified overdamped water manometers used in earlier studies had some significant limitations. They did not allow either for the observation of pleural pressure oscillations associated with respiratory cycle or for the precise measurement and registration of instantaneous pleural pressure [25]. Introduction of new systems based on electronic pressure transducers opened new possibilities to study pleural pathophysiology during pleural fluid removal [14, 26-29]. This refers not only to the measurement of instantaneous pleural pressure but also to data display, registration and analysis $[2,16,18,30]$. Electronic manometers had very low inertia and high frequency of measurements $(50 \mathrm{~Hz})$ allowing reliable measurements of pleural pressure even during cough [17]. The use of electronic systems of pleural pressure registration allows very precise and detailed analysis of pleural pressure curve, as showed in our study and the paper by Boshuizen et al. [18]. We believe that further developments in monitoring of different parameters of respiratory system will help to precisely explain the pathophysiological effects of pleural fluid accumulation and its removal. 
We are aware about some limitations of our study. First, the investigated group was relatively small. The limited number of patients does not allow a full assessment of $\mathrm{Ppl}_{\mathrm{ampl}}$ and RR characteristics in subgroups presenting different patterns of changes. Very small groups of patients with inconsecutive increase in $\mathrm{Ppl}_{\mathrm{ampl}}$ (only 3 patients) and $\mathrm{Ppl}_{\mathrm{ampl}}$ decrease in the last phase of the procedure (5 patients) do not allow a reliable comparative analysis between of different variables in those groups. Second, as the vast majority of our patients had malignant pleural effusion we cannot be sure that the characteristics of $\mathrm{Ppl}_{\mathrm{ampl}}$ and RR changes would be similar in patients with non-malignant pleural effusion. Third, the analysis of $\mathrm{Ppl}_{\mathrm{ampl}}$ and $\mathrm{RR}$ changes in relation to the relative volume of withdrawn pleural effusion (\% of the total volume removed in individual patients) may be questioned. However, this method of analysis was applied to make our results relatively independent of the absolute volume of removed pleural fluid. This approach was based on the assumption that in all patients therapeutic thoracentesis is a complete procedure independently of the volume of the withdrawn pleural fluid and justified the comparison of the procedures of removal of different volumes of pleural fluid. In our opinion, the analysis of $\mathrm{Ppl}_{\mathrm{ampl}}$ and $\mathrm{RR}$ as the function of absolute volume of removed pleural fluid in patients with removed pleural fluid volume ranging from 500 to $4250 \mathrm{ml}$ would be even more controversial.

\section{Conclusions}

In conclusion, therapeutic thoracentesis is associated with significant changes not only in pleural pressure but also in pleural pressure amplitude during the respiratory cycle. Contrary to pleural pressure, the pleural pressure amplitude steadily increases in the vast majority of patients. The significance of $\mathrm{Ppl}_{\mathrm{ampl}}$ and RR changes associated with pleural fluid withdrawal should be elucidated in further studies.

\footnotetext{
Abbreviations

CXR: chest radiograph; end-exp Ppl: end-expiratory pleural pressure; end-insp Ppl: end-inspiratory pleural pressure; $\mathrm{FEV}_{1}$ : forced expiratory volume at first second; FVC: forced vital capacity; IQR: interquartile range; PE: pleural elastance; PF: pleural fluid; Ppl: pleural pressure; Pplampl: pleural pressure amplitude; RR: respiratory rate
}

\section{Acknowledgements}

Not applicable.

\section{Funding}

The study was supported by a research grant from the National Science Centre, Poland (Grant No. 2012/05/B/NZ5/01343). The funding body had no role in the study design, data collection, analysis and interpretation, as well as in manuscript preparation and decision to publish.

\section{Availability of data and materials}

The datasets used and analysed during the current study are available from the corresponding author on reasonable request.

\section{Authors' contributions}

EMG, PK, TG, RK designed the study. MZK, EMG performed the literature search, MZK, EMG, PK, RK were responsible for patient recruitment, MZK, EMG, MM, KZ, PK, AS, RK performed therapeutic thoracentesis and pleural pressure measurements during the procedure, EMG, MM, KZ, AS, TG prepared a database, MZK, EMG, MM, KZ, AS, TG, RK were involved in data analysis and interpretation. MZK, EMG, TG, RK wrote the first draft of the manuscript, all authors critically reviewed the manuscript, contributed to and approved the final version.

\section{Ethics approval and consent to participate}

The study was approved by the Institutional Review Board (Bioethics Committee) of the Medical University of Warsaw, approval number: KB 105/ 2012. All participant signed an informed consent for pleural pressure measurements during and after therapeutic thoracentesis, as well as for all additional monitoring procedures (including ECG, lung function testing, pulse oximetry and continuous transcutaneous measurements of oxygen and carbon dioxide pressure) that were prespecified in the protocol of the study.

\section{Consent for publication}

Not applicable.

\section{Competing interests}

The authors declare that they have no competing interests

\section{Publisher's Note}

Springer Nature remains neutral with regard to jurisdictional claims in published maps and institutional affiliations.

\section{Author details}

${ }^{1}$ Department of Internal Medicine, Pulmonary Diseases \& Allergy, Medical University of Warsaw, Banacha 1a, 02-097 Warsaw, Poland. ${ }^{2}$ Nalęcz Institute of Biocybernetics and Biomedical Engineering, Polish Academy of Sciences, Ks. Trojdena 4, 02-109 Warsaw, Poland.

Received: 29 August 2017 Accepted: 29 January 2018

Published online: 14 February 2018

\section{References}

1. Light RW. Physiology: changes with pleural effusion and pneumothorax. In Textbook of pleural Diseases. 2nd ed. Ed. Light RW, Gary Lee YC. Hodder Arnold an Hachette UK Company, London 2008.

2. Feller-Kopman D, Parker MJ, Schwartzstein RM. Assessment of pleural pressure in the evaluation of pleural effusions. Chest. 2009:135:201-9.

3. Feller-Kopman D. Therapeutic thoracentesis: the role of ultrasound and pleural manometry. Curr Opin Pulm Med. 2007:13:312-8.

4. Light RW, Stansbury DW, Brown SE. The relationship between pleural pressures and changes in pulmonary function after therapeutic thoracentesis. Am Rev Respir Dis. 1986;133:658-61.

5. Cartaxo AM, Vargas FS, Salge JM, Marcondes BF, Genofre EH, Antonangelo L, Marchi E, Teixeira LR. Improvements in the 6-min walk test and spirometry following thoracentesis for symptomatic pleural effusions. Chest. 2011;139: 1424-9.

6. Duszak R Jr, Chatterjee AR, Schneider DA. National fluid shifts: fifteen-year trends in para-centesis and thoracentesis procedures. J Am Coll Radiol 2010; 7:859-864.

7. Pannu J, DePew ZS, Mullon JJ, Daniels CE, Hagen CE, Maldonado F. Impact of pleural manometry on the development of chest discomfort during thoracentesis: a symptom-based study. J Bronchology Interv Pulmonol. 2014;21:306-13.

8. Estenne M, Yernault JC, De Troyer A. Mechanism of relief of dyspnea after thoracocentesis in patients with large pleural effusions. Am J Med. 1983;74: 813-9.

9. Wang JS, Tseng $\mathrm{CH}$. Changes in pulmonary mechanics and gas exchange after thoracentesis on patients with inversion of a hemidiaphragm secondary to large pleural effusion. Chest. 1995:107:1610-4.

10. Zerahn B, Jensen BV, Olsen F, Petersen JR, Kanstrup IL. The effect of thoracentesi on lung function and transthoracic bioimpedance. Respir Med. 1999;93:196-201.

11. Brandstetter RD, Cohen RP. Hypoxemia after thoracentesis. A predictable and treatable condition. JAMA. 1979;242:1060-1. 
12. Perpiñá M, Benlloch E, Marco V, Abad F, Nauffal D. Effect of thoracentesis on pulmonary gas exchange. Thorax. 1983;38:747-50.

13. Agustí AG, Cardús J, Roca J, Grau JM, Xaubet A, Rodriguez-Roisin R. Ventilation-perfusion mismatch in patients with pleural effusion: effects of thoracentesis. Am J Respir Crit Care Med. 1997;156:1205-9.

14. Doelken P, Abreu R, Sahn SA, Mayo PH. Effect of thoracentesis on respiratory mechanics and gas exchange in the patient receiving mechanical ventilation. Chest. 2006;130:1354-61.

15. Chen WL, Chung CL, Hsiao SH, Chang SC. Pleural space elastance and changes in oxygenation after therapeutic thoracentesis in ventilated patients with heart failure and transudative pleural effusions. Respirology. 2010;15:1001-8.

16. Krenke R, Guc M, Grabczak EM, Michnikowski M, Pałko KJ, Chazan R, Gólczewski T. Development of an electronic manometer for intrapleural pressure monitoring. Respiration. 2011;82:377-85.

17. Zielińska-Krawczyk M, Michnikowski M, Grabczak EM, Pałko KJ, Korczyński P, Gólczewski T, Krenke R. Cough during therapeutic thoracentesis - friend or foe? Respirology. 2015;20:166-8.

18. Boshuizen RC, Sinaasappel M, Vincent AD, Goldfinger V, Farag S, van den Heuvel MM. Pleural pressure swing and lung expansion after malignant pleural effusion drainage. the benefit of high-temporal resolution pleural manometry J Bronchology Interv Pulmonol. 2013;20:200-5.

19. Ahmed SH, Ouzounian SP, Dirusso S, Sullivan T, Savino J, Del Guercio L. Hemodynamic and pulmonary changes after drainage of significant pleural effusions in critically ill, mechanically ventilated surgical patients. J Trauma. 2004;57:1184-8.

20. Argento AC, Murphy TE, Pisani MA, Araujo KL, Puchalski J. Patient-centered outcomes following thoracentesis. Pleura (Thousand Oaks). 2015;2:1-12.

21. Thomas R, Jenkins S, Eastwood PR, Lee YC, Singh B. Physiology of breathlessness associated with pleural effusions. Curr Opin Pulm Med. 2015; 21:338-45.

22. Burki NK, Lee LY. Mechanisms of dyspnea. Chest. 2010;138:1196-201.

23. Light RW, Jenkinson SG, Minh VD, George RB. Observations on pleural fluid pressures as fluid is withdrawn during thoracentesis. Am Rev Respir Dis. 1980;121:799-804.

24. Lan RS, Lo SK, Chuang ML, Yang CT, Tsao TC, Lee CH. Elastance of the pleural space: a predictor for the outcome of pleurodesis in patients with malignant pleural effusion. Ann Intern Med. 1997;126:768-74.

25. Doelken P, Huggins JT, Pastis NJ, Sahn SA. Pleural manometry: technique and clinical implications. Chest. 2004;126:1764-9.

26. Huggins JT, Sahn SA, Heidecker J, Ravenel JG, Doelken P. Characteristics of trapped lung. Pleural fluid analysis, manometry, and air-contrast chest CT. Chest. 2007;131:206-13.

27. Feller-Kopman D, Walkey A, Berkowitz D, Ernst A. The relationship of pleural pressure to symptom development during therapeutic thoracentesis. Chest. 2006:129:1556-60

28. Feller-Kopman D, Berkowitz D, Boiselle P, Ernst A. Large-volume thoracentesis and the risk of reexpansion pulmonary edema. Ann Thorac Surg. 2007;84:1656-61.

29. Feller-Kopman D. Point: should pleural manometry be performed routinely during thoracentesis? Yes. Chest. 2012;141:844-5.

30. Lee HJ, Yarmus L, Kidd D, Ortiz R, Akulian J, Gilbert C, Hughes A, Thompson $R E$, Arias $S$, Feller-Kopman D. Comparison of pleural pressure measuring instruments. Chest. 2014;146:1007-12.

\section{Submit your next manuscript to BioMed Central and we will help you at every step:}

- We accept pre-submission inquiries

- Our selector tool helps you to find the most relevant journal

- We provide round the clock customer support

- Convenient online submission

- Thorough peer review

- Inclusion in PubMed and all major indexing services

- Maximum visibility for your research

Submit your manuscript at www.biomedcentral.com/submit

C Biomed Central 